\title{
The Use of TAAB in Out-of-Print Book Searching
}

Mr. Jacob is order librarian, Michigan State College Library.

$\mathrm{H}^{\circ}$ OW TO ACQUIRE out-of-print publications fairly expeditiously and at reasonable prices is a perennial problem in college and university libraries. With enrollments increasing and graduate and research programs being expanded the demand for books and monographs no longer available from the publishers is a growing one. Usually the publications are needed for special research and graduate program activities. There is, however, a constant demand for certain titles needed for undergraduate reserve reading lists. The filling-in of the library's holdings, generally, also necessitates some provision for the acquisition of out-of-print materials.

In the libraries of larger institutions the accumulation of order cards for outof-print items can assume alarming proportions within a few years' time. The criteria, of course, that determine which items requested shall go into desiderata lists will affect the size of the accumulation. If a library were to consider all items routinely requested, but found to be out of print, and all items from second-hand dealers' catalogs reported "sold" as legitimate searching items, the desiderata lists would naturally grow quickly. If, on the other hand, the burden of urgency is placed on the requester, the lists are usually kept manageable. Second-hand dealers' items reported "sold" may be so reported to the requester with or without the suggestion that the item can be searched for. A routine request for an item found to be out of print may be returned to the faculty member concerned either with the simple notation that it is out of print or with a form slip suggesting that if the item is urgently needed it can be searched for. In any case some control over the size of desiderata lists and some provision for occasional weeding of searching files are desirable.

There are, of course, various methods of searching for out-of-print books. The commonest procedure, probably, is to type a-list of items from the order cards and to submit it to an established dealer who offers a searching service. It is desirable, in this case, to keep a carbon of the list which can be checked as items are offered and which can give a quick indication of the progress of the searching effort. Some libraries put a time limit on the list and notify the dealer to this effect. The unlocated items are then listed with another dealer.

Another method of handling the outof-print problem involves members of the library staff indirectly doing their own searching. ${ }^{1}$ Order cards are filed into a desiderata file in the order department and newly received dealers' catalogs are regularly checked against this file. It is argued that with this method a fair percentage of books are found expeditiously and that the prices are lower than if a searching service has to find specific books on a specific list.

There are, of course, other methods of finding out-of-print books and there are

\footnotetext{
1 Maurice F. Tauber, "Desiderata Files," StechertHafner Book News, V (October, 1950), 2.
} 
permutations and combinations involving these and also involving such things as subject specialization and dealers who specialize. It is proposed, however, in this short paper, to treat a method used by some libraries and one which has seemed, in our experience with it at Michigan State College, to be superior to other methods in numerous respects. Other libraries, doubtless, have used this procedure more extensively than we have; however, it is hoped that a specific account of results obtained by us over a period of several years may be of interest.

I should like to report on our experience with the searching service offered by $T A A B$ Weekly which is also variously known as The American Antiquarian Booksellers' Weekly and as The Library Bookseller. This publication is a kind of weekly depository of library want lists and is circulated from its office in Philadelphia $^{2}$ to around 125 booksellers. The participating book dealers are somewhat concentrated in the New York-Philadelphia area. However, many dealers in New England, the Middle West, the West Coast and some even in Great Britain are active in the project. When want lists are received from libraries they are inserted, free of charge, usually within a week or so. Long lists are staggered over several issues of $T A A B$.

In approximately two weeks dealers begin quoting directly to the library on its want list. The quoting progresses alphabetically down the want list and this facilitates the clerical work of coordinating the quotations. Under our procedure, when quotation cards are received, order cards corresponding to the items quoted on are withdrawn from the desiderata file. The items on our carbon copy of the typed want list are checked as quotations are received so that as new offers are received in the days following, we can see at a glance whether the order

${ }^{2}$ Address : 529 South Melville Street. card has been removed previously.

It is advantageous to have a large table, or some spacious area (to offer a homely suggestion), in order that quotation cards and order cards can be laid out for coordinating and comparison purposes. One title may be offered five or ten times over a period of a week or so. Also, some dealers offer eight or ten items on one card while others will quote on just one title. A decision has to be made among the various quotations not only on the price but also on the most favorable grouping of the orders. That is, a slightly higher price may be paid for one item because it can be bought with three or four other titles from the same dealer thus reducing overhead on the processing of orders.

When a decision has been made on an individual offer the dealer's card can be returned with the request either to send the item or to hold it for an official order. Our practice is to return all cards when the items are not taken, with notations that lower quotations or earlier offers were received.

Over a period of several years we have sent $T A A B$ seven want lists. The subject matter has been quite general in character. There has been some concentration in the areas of English and American literature, history, Americana, public speaking, business education and, to some extent, in pure and applied science. As indicated earlier, quotations were received in about two to three weeks after the lists were sent in. The results on the lists were as follows: list 1, 80 titles listed, 27 quoted on; list 2, 111 titles, 68 quoted on; list 3, 507 titles, 258 quoted on; list 4, 88 titles, 47 quoted on; list 5, 48 titles, 15 titles quoted on; list 6, 781 titles, 363 quoted on; list 7 , 123 titles, 54 quoted on. The overall figure is 832 titles quoted on out of 1738 titles listed, or $47 \%$. The library accepted about $90 \%$ of the titles offered and the average price paid per title was $\$ 4.48$. 
An important feature of $T A A B$ service is the competitive aspect of the quotations. In the opinion of the writer the majority of the offers could be described as "quite reasonable." In many cases, as might be expected, the prices were actually lower than the original list prices. In other cases where the prices asked were somewhat higher, especially where there were few quotations or only one, it was difficult to judge as to reasonableness. An interesting sidelight was the consistency with which a few dealers almost always overpriced their offers. Needless to say, unless these items were desperately needed they were refused.

This paper does not present any statistical comparisons between the $T A A B$ method of acquiring out-of-print books and the method involving the use of a single searcher. In order to achieve a valid comparison with regard to speed of acquisition and to prices, the same list of titles would have to be used in both methods. However, if personal experience leading to definite impressions about both procedures can be the basis of comparison, the comments that follow may be of some value.

I should like to summarize what seem to be the advantages and the disadvantages of the $T A A B$ method of finding out-of-print books. In the first place, an appreciable percentage of titles can be secured expeditiously. The fact that within three or four weeks approximately a hundred dealers see the want list assures that action will be prompt. It would seem unlikely that a single searcher could have the clerical help to equal $T A A B$ 's performance in this respect.

As has been indicated before, $T A A B$ service, with a competitive quotation system in effect, provides titles on the whole at reasonable prices. It is not a little illuminating to observe the trend of prices on specific titles and it is interesting that often a majority of quotations will be at the lowest figure.

There are certain disadvantages in the
$T A A B$ approach. It might be thought of as an expeditious, intensive, but shortlived method. The quotations come in steadily until the list is covered. Thereafter, practically no further quotations will be received. The order librarian must then re-list the titles not secured either with a single searcher or, after a lapse of time, again with $T A A B$. This may involve considerable extra clerical work. A single dealer service will usually be a long-time effort and will be clearly preferable in this respect.

During the intensive but short-lived response to a list there is a concentrated work load put upon the order department in coordinating the offers, making the decisions on them, and attending to all the clerical details involved. In cases where a particular edition of a book is wanted, it must be ascertained whether the quotation is for the correct edition. Since numerous dealers are involved, accuracy in linking the correct dealer with the specific titles must be observed. Finally, although we did not list many foreign language titles with $T A A B$, relatively few of the ones we listed were found.

A few suggestions regarding the use of $T A A B$ service may be of value. For most general want lists it would seem that a combination of the use of $T A A B$, as first, and a single dealer for the remaining titles would be effective. Some libraries might find $T A A B$ useful only for out-of-print titles needed urgently, in which case other desiderata items could be listed with a slower but more persistent service. Also, certain differentials regarding subject matter might be observed. $T A A B$ 's performance is undoubtedly best for general, English language material. Lastly, a suggestion would be that more short lists be sent to $T A A B$ rather than fewer long lists. A long list can be broken up and sent at intervals to prevent too continuous a work load due to the intensive short-run response (Continued on page 40) 
that the Library of Congress printed catalog does not by any manner of means include all the references in the Library of Congress card catalogs, a precedent which might well hold for the published National Union Catalog. And for entries under a variety of forms, the editors must do their best and allowance must be made in the published work for a certain amount of inconsistency. It would be easy to spend millions of dollars in editing the catalog, but this must be avoided. A bird in the hand is worth two in the bush.

The intent of this paper is to urge the acceptance of a limited program for the publication of the National Union Catalog. In essence the publication would be complementary to the Library of Congress printed catalog, as well as to the various other accepted bibliographies. It would not be a complete and perfect bibliography, but it would be a tremendously valuable bibliographical tool, both for the location of copies and for the compilation of bibliographies of various kinds. With the proposed expansion of the Library of Congress $\mathrm{Au}$ thor Catalog into a union catalog, beginning next year, the time has come to reproduce the retrospective National Union Catalog to the best of our ability. If general agreement can be reached on this proposal, we could ask the Library of Congress to study the costs involved, to estimate the size of the subsidy, if any, that would be required, to make possible a publication at a low enough price so that the whole project would become feasible.

\section{Future Program}

\section{(Continued from page 12)}

provide readers with information on developments in the audio-visual field. A number of readers have already expressed favorable comments on this new feature. Librarians in practice can assist in improving the journal by writing and by encouraging their staff members to write. If there is any single criterion to guide writers, it is to present new ideas. Contributors should follow the basic style of the journal in presentation, footnote citations, and tabular organization. We are counting on your full cooperation.-Maurice F. Tauber, Editor.

\section{Faculty Service}

\section{(Continued from page 15)}

ject specialists, but the functions of the specialist might well be performed immediately under the office of the director, or out of a subject divisional library, or out of a departmental library. It is believed, however, that once the service is created the confidence and support necessary to its success would soon be established in sufficient degree to make the innovation successful.

Certainly the librarian convinced of the efficacy of his calling will not cringe at improving or increasing services. Let the faint-hearted but look back over the progress of the last half-century and see how far he has come already. He should note also that special libraries have always given most of the services discussed above. Indeed, the coordination of faculty services entails little more than the adaptation of certain special library practices to an academic situation.

\section{Use of TAAB}

\section{(Continued from page 18)}

which $T A A B$ service provides.

In conclusion, it might be said that the $T A A B$ method has the virtue of being cooperative, comprehensive and competitive. It is cooperative in the sense that libraries and booksellers derive mutual benefit in a new and imaginative way. Comprehensiveness is achieved by the large-scale attention given by booksellers to an individual library's wants. It is competitive because of the number of dealers involved and this tends to encourage low quoting on items desired. The method has much to recommend it. 